\title{
Preparation of para-Aminophenol from Nitrobenzene through Bamberger Rearrangement using a Mixture of Heterogeneous and Homogeneous Acid Catalysts
}

Roxan Joncour, ${ }^{a}$ Amadéo Ferreira, ${ }^{b}$ Nicolas Duguet, ${ }^{a} *$ and Marc Lemaire ${ }^{a, *}$

${ }^{a}$ Univ Lyon, Université Claude Bernard Lyon1, CNRS, INSA-Lyon, CPE- Lyon, Institut de Chimie et Biochimie Moléculaires et Supramoléculaires, (ICBMS), UMR 5246, Equipe CAtalyse,

SYnthèse et ENvironnement (CASYEN), 43 boulevard du 11 novembre 1918, F-69622 Villeurbanne Cedex, France.

${ }^{b}$ Minakem SAS, 145 chemin des Lilas, 59310 Beuvry-la-Forêt, France. 


\section{TABLE OF CONTENTS GRAPHIC}

para-Aminophenol has been prepared from nitrobenzene through Bamberger rearrangement using a mixture of $\mathrm{NbO}_{x} / \mathrm{SiO}_{2}$ and $\mathrm{H}_{2} \mathrm{SO}_{4}$ and was isolated with $84 \%$ yield (based on the recovered starting material) and 97\% HPLC purity.

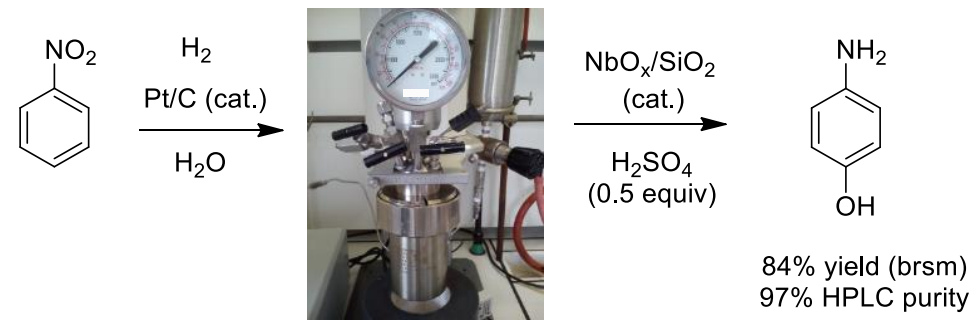


ABSTRACT: The direct preparation of para-aminophenol (PAP) from nitrobenzene (NB) through Bamberger rearrangement was studied in biphasic medium using a mixture of $\mathrm{NbO}_{x} / \mathrm{SiO}_{2}$ and $\mathrm{H}_{2} \mathrm{SO}_{4}$ as an acid catalyst. After optimization of the reaction parameters, PAP was obtained with $85-88 \%$ selectivity that is representing a $10 \%$ selectivity improvement by comparison with sulphuric acid alone. The optimized conditions were implemented in a scale-up reaction and PAP was isolated with $84 \%$ yield (based on the recovered starting material) and 97\% HPLC purity. Overall, this process requires less sulphuric acid than the traditional process, leading to a drastic reduction of the saline waste.

KEYWORDS: Nitrobenzene, Hydrogenation, Bamberger rearrangement, para-Aminophenol, Acid catalysis 


\section{INTRODUCTION}

para-Aminophenol (PAP) is an industrially-relevant intermediate for the synthesis of drugs, pesticides, dyes and photographic materials. ${ }^{1}$ Whereas this last activity has almost completely disappeared since the advent of the digital age, the production of PAP is mainly driven by the manufacture of paracetamol (acetaminophen). Indeed, this analgesic and antipyretic drug is one of the most consumed drugs worldwide with an estimated production of almost 150,000 tons per year. ${ }^{2}$ Recently, we have reported that paracetamol can be prepared in one step by direct amidation of hydroquinone ${ }^{3}$ but, so far, most industrial routes rely on the acylation of PAP as final stage, thus giving a crucial role to this intermediate. PAP can be prepared by reduction of $p$ nitrophenol using Bechamp conditions $(\mathrm{Fe} / \mathrm{HCl})$, however, this method generates a large amount of waste. ${ }^{4}$ Alternatively, catalytic hydrogenation of $p$-nitrophenol could furnish PAP in a much cleaner way but the overall route is still plagued by the low selectivity of the nitration of phenol. ${ }^{5}$ The catalytic hydrogenation of nitrobenzene to phenylhydroxylamine (PHA) and subsequent Bamberger rearrangement ${ }^{6}$ in acidic aqueous conditions affords PAP with usually highly selectivity for the para position as only a few percent of ortho-aminophenol (OAP) are produced. However, aniline (AN) is the main byproduct of the hydrogenolysis of PHA (Scheme 1). ${ }^{7}$ Advantageously, this process occurs through a single-step operation, as a result, it provides an economical and straightforward access to PAP, which has been industrialized by Mallinckrodt Inc. $^{8}$ 


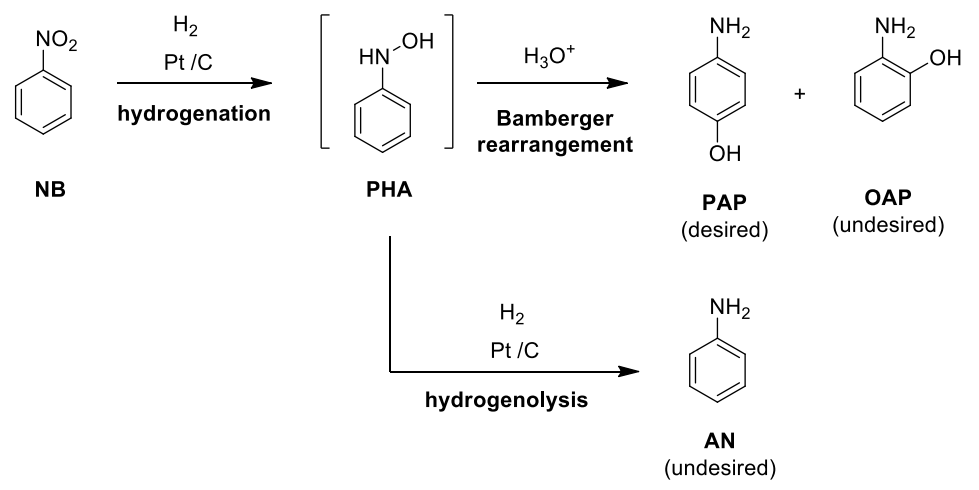

Scheme 1. para-Aminophenol from nitrobenzene through hydrogenation / Bamberger rearrangement.

A range of (supported) noble metals such as $\mathrm{Pt}, \mathrm{Pd}, \mathrm{Rh}, \mathrm{Ru}$ and $\mathrm{Au}$ has been reported for the selective hydrogenation of nitrobenzene to PAP. ${ }^{9,10}$ Among them, platinum is considered as the best in terms of PAP selectivity, low loading and high reaction rate. ${ }^{11}$ Recently, nickel catalysts have also been investigated as cheaper alternatives but these systems require high catalyst loading. ${ }^{12}$ Sulfuric acid is classically used as catalyst for the Bamberger rearrangement of PHA. ${ }^{11}$ However, its corrosive nature is deleterious for the pressurized reactor that is essential for the hydrogenation step. Moreover, stoichiometric amount (and more) of this "catalyst" is required as PAP and aniline are obtained as hydrogen sulfate salts. Consequently, the reaction mixture should be neutralized by ammonia to recover free PAP thus leading to a large amount of diluted ammonium sulfate aqueous solution.

To address these issues, several attempts have been made to substitute sulfuric acid by solid acid catalysts. Mechanical mixtures of supported Pt catalyst with ion exchange resins or heteropolyacids, ${ }^{13} \mathrm{SO}_{4}{ }^{2-} / \mathrm{ZrO}_{2}-\mathrm{Al}_{2} \mathrm{O}_{3},{ }^{14}$ supported aluminophosphate (SAPO), ${ }^{15} \mathrm{SO}_{3} \mathrm{H} / \mathrm{C}^{16}$ were reported. However, the selectivity in PAP is usually low to moderate. An excellent selectivity ( $>$ 90\%) can only be attained using zirconium sulfate. ${ }^{17}$ However, this solid acid is readily soluble 
in water, ${ }^{18}$ thus releasing sulfuric acid in solution. Bifunctional catalysts such as $\mathrm{Pt} / \mathrm{H}-\mathrm{SZM}-5,{ }^{19}$ $\mathrm{Pt}-\mathrm{S}_{2} \mathrm{O}_{8}{ }^{2-} / \mathrm{ZrO}_{2}{ }^{20}$ and $\mathrm{Pb}-\mathrm{Pt} / \mathrm{MgAPO}^{21}$ were also reported as alternatives but none of these systems can efficiently produce PAP with high selectivity. Finally, carbonic acid generated in pressurized $\mathrm{CO}_{2} / \mathrm{H}_{2} \mathrm{O}$ system was recently used in association with platinum catalysts. This protocol is very attractive from an ecological point of view, but high PAP selectivity could only be reached at very low conversion $(<20 \%){ }^{22}$

Niobium-based catalysts have great potential in heterogeneous catalysis. ${ }^{23}$ More particularly, niobium oxides usually exhibit acidic properties with Hammet acidities estimated to $\mathrm{H}_{0} \leq-5.6$ for $\mathrm{Nb}_{2} \mathrm{O}_{5} . \mathrm{H}_{2} \mathrm{O}^{24}$ and $\mathrm{H}_{0} \leq-8.2$ for $\mathrm{NbOPO}_{4} .{ }^{23}$ Consequently, they have been used in a range of acid-catalyzed organic transformations such as dehydration, ${ }^{25}$ aldol condensation, ${ }^{26}$ benzylic substitutions ${ }^{27}$ or esterification reactions. ${ }^{28}$ Heterogeneous niobium-based catalysts have also been reported to catalyze similar reactions, ${ }^{29}$ however, they have been largely underexploited. Nevertheless, they have recently found applications in the hydrolysis of saccharose ${ }^{30}$ the lactonisation of ethyl levulinate, ${ }^{31}$ and in the Beckman rearrangement. ${ }^{32}$ However, to the best of our knowledge, (supported) niobium catalysts have never been employed for the Bamberger rearrangement of PHA to PAP. We report here the use $\mathrm{NbO}_{x} / \mathrm{SiO}_{2}$ as an acid co-catalyst for the direct reduction of nitrobenzene to PAP. Moreover, we describe a synergic effect between this heterogeneous catalyst and a homogeneous mineral acid that has a positive influence on the selectivity of the reaction. 


\section{RESULTS AND DISCUSSION}

In order to optimize this process, it is necessary to consider both the chemical and the physicochemical aspects of this transformation. The reduction of NB to PAP is assumed to occur in a multi-phasic medium where nitrobenzene droplets are dispersed in water and are acting as microreactors (Figure 1). This model has been first proposed by Augustine et al. ${ }^{11 \mathrm{c}}$

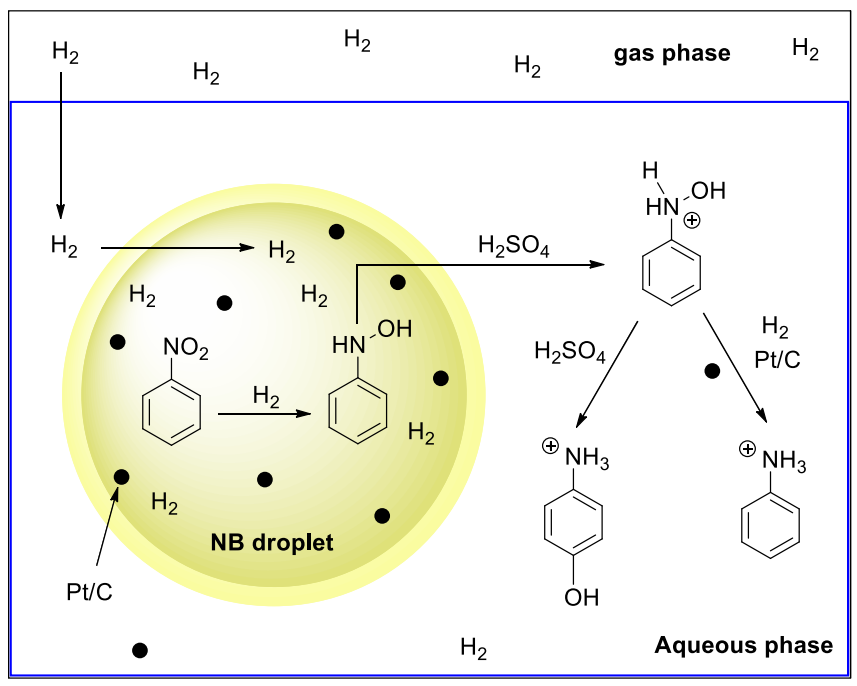

Figure 1. Reduction of NB to PAP in a multi-phasic medium.

The hydrogenation of NB to PHA takes place in the NB droplets where the hydrophobic $\mathrm{Pt} / \mathrm{C}$ is present and the hydrogen concentration is maximal. ${ }^{33}$ Once produced, hydrophilic PHA migrates to the water phase through protonation and undergoes acid-catalysed Bamberger rearrangement to give protonated PAP. From this model, one could understand that if PHA stands too long in the NB droplets, it undergoes over-reduction to give AN as the byproduct. It is thus essential that the rate of migration of PHA is high in order to reach high selectivity. From this model, only the acid acting as catalyst for the Bamberger rearrangement could be substituted by a heterogeneous catalyst as the presence of a Bronsted acid is essential to favour the migration of PHA in the 
water phase through protonation. Consequently, we envisioned that a mixture of heterogeneous and homogeneous acid catalysts could be beneficial for the selectivity of this transformation.

To test this hypothesis, $\mathrm{NbO}_{\mathrm{x}} / \mathrm{SiO}_{2}$ was first prepared following a reported procedure ${ }^{32 \mathrm{~d}}$ by impregnation of a $\mathrm{Nb}^{\mathrm{V}}$ precursor $\left[\mathrm{Nb}(\mathrm{OEt})_{5}\right]$ onto a silica with a specific area of about $395 \mathrm{~m}^{2} \cdot \mathrm{g}^{-}$ ${ }^{134}$ Three batches were synthesized in order to obtain a Nb/Si molar ratio of 0.24 . These catalysts were characterized by the loss at $1000^{\circ} \mathrm{C}$, ICP-EOS and BET area (Table 1).

Table 1. Characterization of $\mathrm{NbO}_{\mathrm{x}} / \mathrm{SiO}_{2}$ catalysts.

\begin{tabular}{cccccc} 
Entry & $\begin{array}{c}\text { Loss at } \\
\mathrm{NbO}_{\mathrm{x}} / \mathrm{SiO}_{2} \text { catalyst }\end{array}$ & $\begin{array}{c}\% \mathrm{Nb} \\
1000^{\circ} \mathrm{C}(\%)\end{array}$ & $\begin{array}{c}\mathrm{Nb} / \mathrm{Si} \\
(\mathrm{wt} \%)^{a}\end{array}$ & $\begin{array}{c}\mathrm{BET} \text { area } \\
\text { molar ratio }^{b}\end{array}$ & \\
\hline 1 & $\mathrm{NbO}_{\mathrm{x}} / \mathrm{SiO}_{2}-\mathbf{1}$ & 6.5 & 17.2 & 0.15 & 259 \\
2 & $\mathrm{NbO}^{c} / \mathrm{SiO}_{2}-\mathbf{2}$ & 1.9 & 17.4 & 0.15 & 270 \\
3 & $\mathrm{NbO}_{\mathrm{x}} / \mathrm{SiO}_{2}-\mathbf{3}$ & 4.6 & 15.8 & 0.13 & 264
\end{tabular}

${ }^{a}$ Determined by ICP-EOS. ${ }^{b}$ Calculated based on $\%$ Nb. ${ }^{c}$ Determined by nitrogen adsorption at $77 \mathrm{~K}$, followed by desorption at $573 \mathrm{~K}$ under vacuum for 5 hours.

The results show that the synthesis of the catalyst is quite reproducible as the 3 batches exhibit very similar $\mathrm{Nb}$ percentage and specific area. However, the $\mathrm{Nb} / \mathrm{Si}$ molar ratio was calculated to around $0.13-0.15$ indicating that the grafting of the niobium precursor was not complete (about $60 \%$ ). Considering that the acidity of $\mathrm{NbO}_{x} / \mathrm{SiO}_{2}$ is the most important parameter from a catalytic point of view, it has been determined by ammonia temperature-programmed desorption $\left(\mathrm{NH}_{3}-\mathrm{TPD}\right)$. The $\mathrm{NH}_{3}-\mathrm{TPD}$ profile of $\mathrm{NbO}_{x} / \mathrm{SiO}_{2}$, presented in Figure 2, shows a desorption peak 
centered around $220^{\circ} \mathrm{C}$, indicating the presence of weak to medium acidic sites on the surface. This result is fully consistent with those of similar materials reported in the literature such as $\mathrm{Nb}_{2} \mathrm{O}_{5} / \mathrm{SiO}_{2}, \mathrm{Nb}_{2} \mathrm{O}_{5} / \mathrm{SiO}_{2}-\mathrm{Al}_{2} \mathrm{O}_{3}$, or Nb-MCM-41, in which the ammonia desorption peak is usually centered around $200-250^{\circ} \mathrm{C} .^{32 \mathrm{a}, 32 \mathrm{~b}}$ Moreover, considering the broadness of the signal, it could be assumed that the acidity of $\mathrm{NbO}_{\mathrm{x}} / \mathrm{SiO}_{2}$ is widely distributed on the surface.

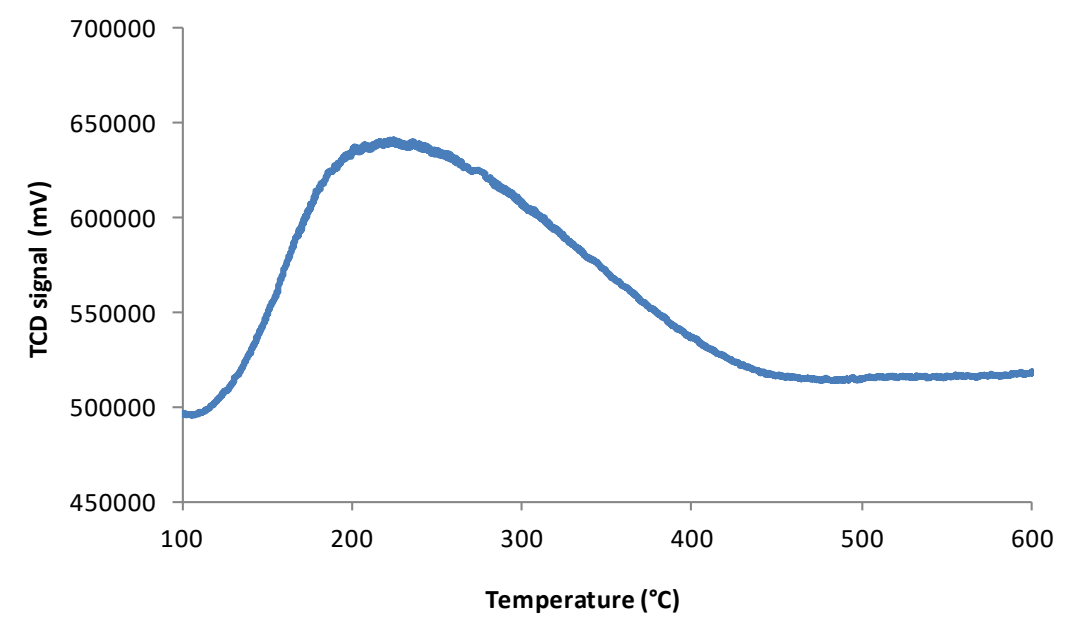

Figure 2. $\mathrm{NH}_{3}-\mathrm{TPD}$ profile of $\mathrm{NbO}_{\mathrm{x}} / \mathrm{SiO}_{2}$.

Finally, the quantification of acid sites of $\mathrm{NbO}_{\mathrm{x}} / \mathrm{SiO}_{2}$ was determined to $190 \mu \mathrm{mol} . \mathrm{g}^{-1}$ after calibration.

The activity of $\mathrm{NbO}_{\mathrm{x}} / \mathrm{SiO}_{2}$ was first investigated in the hydrogenation of $\mathrm{NB}$ to PAP under biphasic conditions at $80^{\circ} \mathrm{C}$ using tetrabutylammonium hydrogensulfate (TBAHS) as a phase transfer agent (Table 2). 
Table 2. Hydrogenation of NB to PAP using heterogeneous and homogeneous acid catalysts. ${ }^{a}$

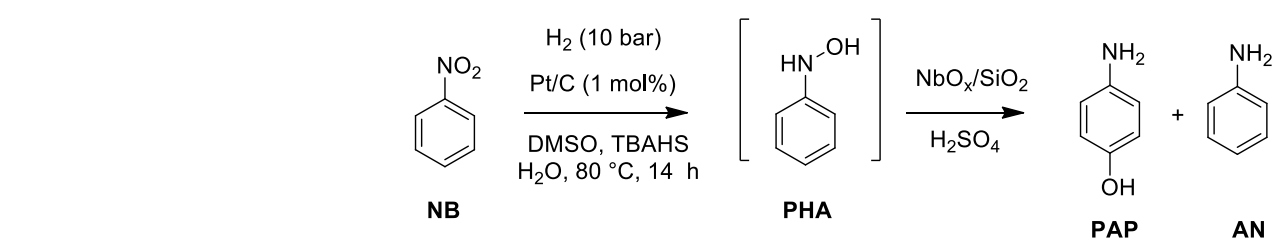

\begin{tabular}{|c|c|c|c|c|c|}
\hline Entry & $\begin{array}{l}\mathrm{H}^{+} / \mathrm{NB} \\
(\mathrm{mol} \%)\end{array}$ & $\begin{array}{c}\mathrm{NbO}_{\mathrm{x}} / \mathrm{SiO}_{2} \\
\text { (g) }\end{array}$ & $\begin{array}{c}\text { Conv. } \mathrm{NB}^{b} \\
(\%)\end{array}$ & $\begin{array}{c}\text { Sel. } \mathrm{PAP}^{b} \\
(\%)\end{array}$ & $\begin{array}{c}\text { Sel. } \mathrm{AN}^{b} \\
(\%)\end{array}$ \\
\hline $1^{c}$ & $0 *$ & 0.2 & 98 & $6^{d}$ & $77^{d}$ \\
\hline 2 & 50 & - & $>99$ & 54 & $n d$ \\
\hline 3 & 100 & - & $>99$ & 76 & 24 \\
\hline 4 & 100 & 0.2 & $>99$ & 84 & 16 \\
\hline 5 & 200 & - & $>99$ & 79 & 21 \\
\hline 6 & 200 & 0.2 & 99 & 86 & 14 \\
\hline
\end{tabular}

${ }^{a}$ Reaction conditions: Stainless steel reactor, $\mathrm{H}_{2}$ (10 bar), NB (9 mL), 1wt $\%-\mathrm{Pt} / \mathrm{C}(20 \mathrm{mg})$, DMSO (6.5 $\mu \mathrm{L})$, TBAHS (0.6 g), $\mathrm{H}_{2} \mathrm{SO}_{4}, \mathrm{NbO}_{\mathrm{x}} / \mathrm{SiO}_{2}, \mathrm{H}_{2} \mathrm{O}(75 \mathrm{~mL}), 80^{\circ} \mathrm{C}, 14$ hours. ${ }^{b}$ Determined by HPLC. ${ }^{c}$ Reaction run for 7 hours. ${ }^{d}$ Selectivity PHA $=6 \%$, selectivity AOB $=$ $9 \%$. ${ }^{*}$ The total acidity for $0.2 \mathrm{~g}$ of catalyst was calculated to $38 \mu \mathrm{mol}$ of acid sites, i.e., 0.04 mol\%/NB. $n d$ : not determined.

Using $0.2 \mathrm{~g}$ of $\mathrm{NbO}_{\mathrm{x}} / \mathrm{SiO}_{2}$, the conversion of $\mathrm{NB}$ reached $98 \%$ but the selectivity of PAP was only $6 \%$ (Table 2 , entry 1 ). This result shows the ability of the catalyst to promote the 
Bamberger rearrangement. However, the acidity of $\mathrm{NbO}_{\mathrm{x}} / \mathrm{SiO}_{2}$ is too weak to reach high selectivity. Actually, in the absence of a proton source, PHA is accumulated in the nitrobenzene phase and is mainly hydrogenated to give AN with $77 \%$ selectivity. The detection of PHA itself (6\%) and azoxybenzene (AOB, 9\%) also confirms the accumulation of PHA. By comparison, using 0.25 equivalent of $\mathrm{H}_{2} \mathrm{SO}_{4}$ with respect to nitrobenzene ( $\left.50 \mathrm{~mol} \% \mathrm{H}^{+} / \mathrm{NB}\right)$, the conversion was complete and PAP was obtained with 54\% selectivity (Table 2, entry 2). The selectivity could be further improved to $76 \%$ when using 0.5 equivalent of $\mathrm{H}_{2} \mathrm{SO}_{4}\left(100 \mathrm{~mol} \% \mathrm{H}^{+} / \mathrm{NB}\right)$ (Table 2, entry 3). As previously envisioned, the combination of $\mathrm{NbO}_{\mathrm{x}} / \mathrm{SiO}_{2}$ with $\mathrm{H}_{2} \mathrm{SO}_{4}$ improved the selectivity to $84 \%$, thus confirming that a Bronsted acid is definitely necessary for a rapid transfer of PHA to the water phase (Table 2, entry 4). The performances of this new system are even better than using 1 equivalent of $\mathrm{H}_{2} \mathrm{SO}_{4},\left(200 \mathrm{~mol} \% \mathrm{H}^{+} / \mathrm{NB}\right)$, giving only $79 \%$ selectivity (Table 2, entry 5). Finally, the synergetic effect was also observed in the latter case, giving a $86 \%$ selectivity (Table 2 , entry 6 ).

The loading of $\mathrm{NbO}_{\mathrm{x}} / \mathrm{SiO}_{2}$ was next investigated (Figure 3).

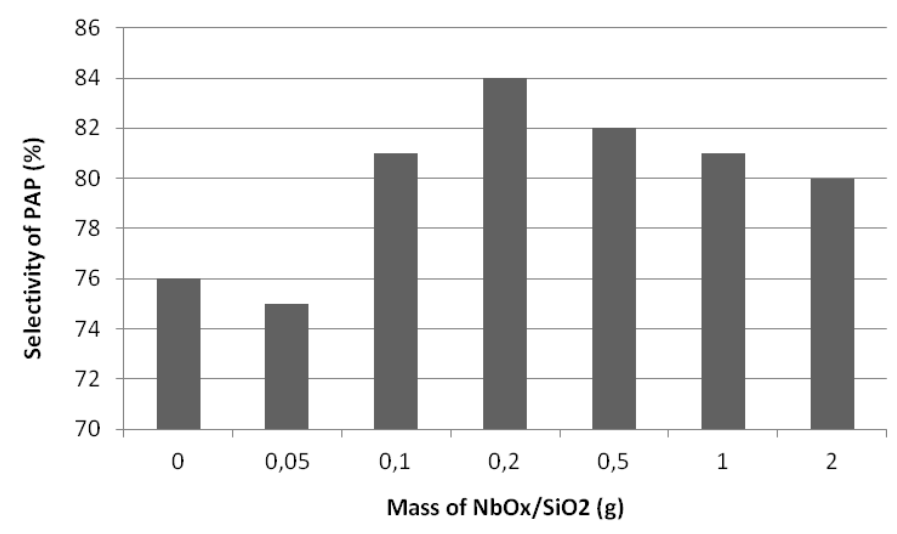

Figure 3. Selectivity of PAP Versus catalyst loading. Reaction conditions: Stainless steel reactor, $\mathrm{H}_{2}(10 \mathrm{bar}), \mathrm{NB}(9 \mathrm{~mL}), 1 \mathrm{wt} \%-\mathrm{Pt} / \mathrm{C}(20 \mathrm{mg})$, DMSO $(6.5 \mu \mathrm{L})$, TBAHS $(0.6 \mathrm{~g}), \mathrm{H}_{2} \mathrm{SO}_{4},(0.5$ 
equiv., $\left.100 \mathrm{~mol} \% \mathrm{H}^{+} / \mathrm{NB}\right), \mathrm{NbO}_{\mathrm{x}} / \mathrm{SiO}_{2}, \mathrm{H}_{2} \mathrm{O}(75 \mathrm{~mL}), 80^{\circ} \mathrm{C}, 14$ hours. The selectivity of PAP was determined determined by HPLC.

From 0 to $0.2 \mathrm{~g}$ ( 0 to $0.4 \mathrm{~mol} \%$ in $\mathrm{Nb}$ ), the selectivity of PAP gradually increased from 76 to $84 \%$. However, no further improvement was observed using larger amounts of catalyst (up to 2 g, i.e. about $4 \mathrm{~mol} \%)$. On the contrary, the selectivity slightly dropped to about $80 \%$. This could be explained by the fact that the stirring of the heterogeneous system becomes less efficient when using a large quantity of solid. As a result, the catalyst loading of $\mathrm{NbO}_{\mathrm{x}} / \mathrm{SiO}_{2}$ was set at 0.2 $\mathrm{g}$ for further optimization.

From previous literature reports, $\mathrm{Pt} / \mathrm{C}$ and $\mathrm{Pt} / \mathrm{SiO}_{2}$ were found the best catalysts for the reduction of NB to PHA whereas Pt/C is more efficient for the direct conversion of NB to PAP. However, Figueras et al. have shown that the support has sometimes little impact on the outcome of the reaction. ${ }^{17}$ Consequently, as the role of the support is quite difficult to predict, a range of heterogeneous platinum catalysts was screened under our conditions (Table 3).

Table 3. Influence of the support of the platinum catalyst. ${ }^{a}$

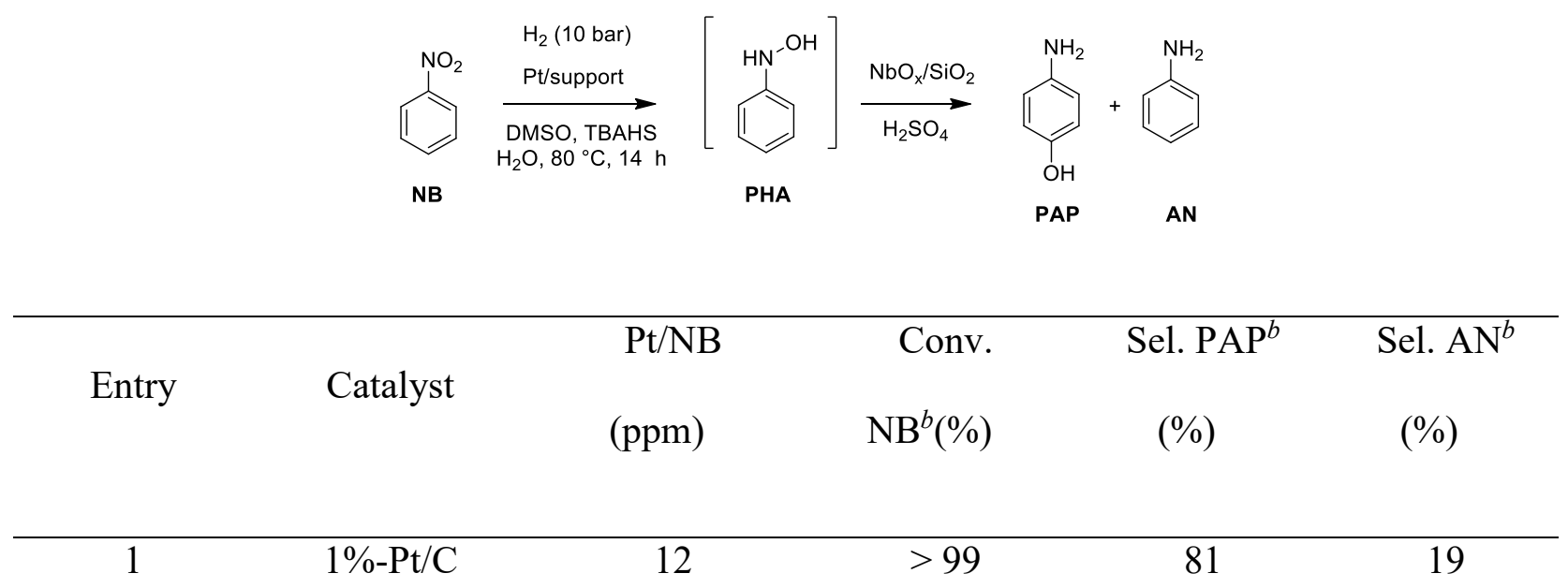




$\begin{array}{cccccc}2^{c} & 1 \%-\mathrm{Pt} / \mathrm{C} & 12 & 50 & 88 & 12 \\ 3 & 5 \%-\mathrm{Pt} / \mathrm{C} & 12 & >99 & 80 & 20 \\ 4^{d} & 5 \%-\mathrm{Pt} / \mathrm{C} & 59 & 42 & 86 & 14 \\ 5 & 5 \%-\mathrm{Pt} / \mathrm{SiO}_{2} & 12 & 9 & 27 & 63 \\ 6 & 5 \%-\mathrm{Pt} / \mathrm{Al}_{2} \mathrm{O}_{3} & 12 & 4 & 63 & 27 \\ 7 & 5 \%-\mathrm{Pt} / \mathrm{ZRS} & 12 & 3 & 71 & 29 \\ 8 & \mathrm{PtO}_{2}-\mathrm{H}_{2} \mathrm{O} & 70 & 19 & 69 & 31\end{array}$

${ }^{a}$ Reaction conditions: Stainless steel reactor, $\mathrm{H}_{2}$ (10 bar), NB (9 mL), DMSO (6.5 $\left.\mu \mathrm{L}\right)$, TBAHS (0.6 g), $\mathrm{H}_{2} \mathrm{SO}_{4}(2.5 \mathrm{~mL}), \mathrm{NbO}_{\mathrm{x}} / \mathrm{SiO}_{2}(1 \mathrm{~g}), \mathrm{H}_{2} \mathrm{O}(75 \mathrm{~mL}), 80^{\circ} \mathrm{C}, 14$ hours. ${ }^{b}$ Determined by HPLC. ${ }^{c}$ Reaction for $2 \mathrm{~h} .{ }^{d}$ Reaction for $5 \mathrm{~h}$.

Using $1 \%-\mathrm{Pt} / \mathrm{C}$, the selectivity reached $81 \%$ at complete conversion and was slightly improved to 88 at only $50 \%$ conversion, respectively (Table 3 , entries $1-2$ ). Similar results could be obtained using 5\%-Pt/C showing that the loading of platinum on charcoal has no significant impact (Table 3, entries 3-4). Others platinum-based catalysts such as $\mathrm{Pt} / \mathrm{SiO}_{2}, \mathrm{Pt} / \mathrm{Al}_{2} \mathrm{O}_{3}$ and $\mathrm{Pt} / \mathrm{ZRS}$ were next tested. These species proved to be very poor catalysts giving very low conversion and low to moderate selectivities (Table 3, entries 5-7). Finally, Adams' catalyst $\left(\mathrm{PtO}_{2} \cdot \mathrm{H}_{2} \mathrm{O}\right)$ was tested for comparison but it also gave moderate results despite a higher loading (Table 3, entry 8). These experiments show that the nature of the platinum support has a great influence on both the conversion and the selectivity. These important disparities could be explained by the difference of polarity between supports and by the biphasic nature of the nitrobenzene/water system. When 
$\mathrm{Pt} / \mathrm{C}$ catalysts are used, the hydrophobic nature of the support would force the catalyst to stand in the nitrobenzene droplets, giving high rate of hydrogenation and thus leading to high conversion of NB. On the contrary, when using hydrophilic supports such as $\mathrm{SiO}_{2}, \mathrm{Al}_{2} \mathrm{O}_{3}$ and $\mathrm{ZRS}$, the catalyst is more likely to be dispersed in the water phase, thus giving low conversion of NB. Moreover, it could also explain why the selectivity towards PAP is low in that case, as PHA could be easily reduced to AN in the water phase.

The effect of the loading of DMSO was next probed (Figure 4). Indeed, this additive usually serves as a catalyst poison to avoid over-reduction of PHA to AN.

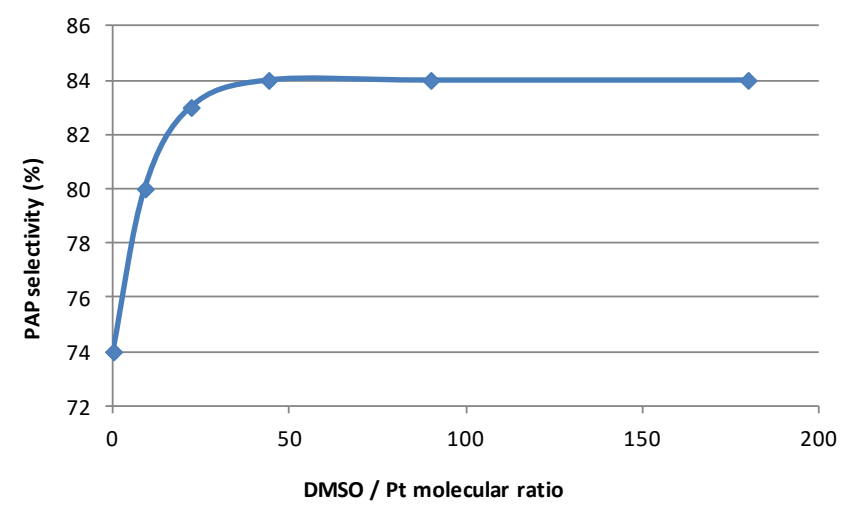

Figure 4. Selectivity of PAP Versus DMSO/Pt molecular ratio. Reaction conditions: Stainless steel reactor, $\mathrm{H}_{2}(10 \mathrm{bar}), \mathrm{NB}(9 \mathrm{~mL}), 1 \mathrm{wt} \%-\mathrm{Pt} / \mathrm{C}(20 \mathrm{mg})$, DMSO $(0-13 \mu \mathrm{L})$, TBAHS $(0.6 \mathrm{~g})$, $\mathrm{H}_{2} \mathrm{SO}_{4}\left(2.5 \mathrm{~mL}, 0.5\right.$ equiv., $\left.100 \mathrm{~mol} \% \mathrm{H}^{+} / \mathrm{NB}\right), \mathrm{NbO}_{\mathrm{x}} / \mathrm{SiO}_{2}(1 \mathrm{~g}), \mathrm{H}_{2} \mathrm{O}(75 \mathrm{~mL}), 80^{\circ} \mathrm{C}, 14$ hours. The selectivity of PAP was determined determined by HPLC.

Without DMSO, the selectivity of PAP only reached $74 \%$. Then, the selectivity increased when the molecular ratio of DMSO relative to Pt was gradually increased from 0 to 45 , thus confirming the importance of this additive in the reduction process. A plateau value was reached at $84 \%$ as no further improvement could be observed using 90 or 180 equivalents of DMSO. As 
a consequence, 90 equivalents of DMSO will be used for further optimization. This value is in accordance with previous works using sulfur derivatives as additives, as values between 20 to 400 could be typically found in the literature. However, these works were performed with higher platinum loading as reported by Caskey (90 to $170 \mathrm{ppm}) 8^{\mathrm{d}-\mathrm{e}}$ or Rylander (1300 ppm). $7^{\mathrm{b}}$

The hydrogen pressure was next studied and it was maintained constant during the experiment (Table 4).

Table 4. Influence of the hydrogen pressure. $^{a}$

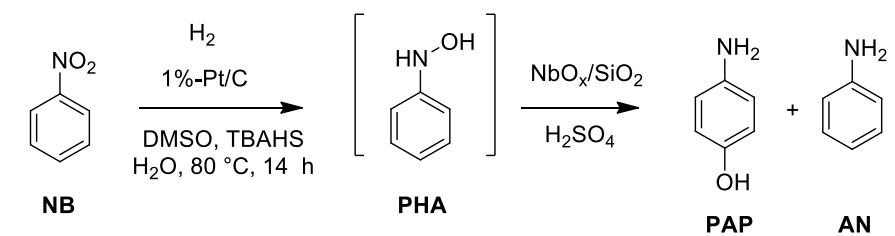

\begin{tabular}{|c|c|c|c|c|}
\hline Entry & $\begin{array}{l}\text { Hydrogen } \\
\text { pressure (bar) }\end{array}$ & Conv. $\mathrm{NB}^{b}(\%)$ & Sel. $\mathrm{PAP}^{b}(\%)$ & Sel. $\mathrm{AN}^{b}(\%)$ \\
\hline 1 & 2.5 & 88 & 83 & 17 \\
\hline 2 & 6 & 98 & 85 & 15 \\
\hline 3 & 10 & $>99$ & 84 & 16 \\
\hline 4 & 20 & $>99$ & 64 & 36 \\
\hline${ }^{a}$ Reaction con & : Stainless steel & tor, $\mathrm{H}_{2}(2.5-20$ & , NB $(9 \mathrm{~mL}), 1$ & $-\mathrm{Pt} / \mathrm{C}(20 \mathrm{mg})$ \\
\hline DMSO $(6.5 \mu \mathrm{I}$ & $\mathrm{AHS}(0.6 \mathrm{~g}), \mathrm{H}_{2}$ & $(2.5 \mathrm{~mL}), \mathrm{NbO}_{\mathrm{x}}$ & $\mathrm{O}_{2}(0.2 \mathrm{~g}), \mathrm{H}_{2} \mathrm{O}$ & $\mathrm{mL}), 80^{\circ} \mathrm{C}, 14$ \\
\hline
\end{tabular}


From 2.5 to 10 bar, the selectivity was quite stable, around $83-85 \%$, but the conversion of NB was only complete using 10 bar of hydrogen (Table 4, entries 1-3). However, the selectivity considerably dropped to $64 \%$ when increasing the hydrogen pressure to 20 bar (Table 4, entry 4). This shows that the accumulation of hydrogen should be avoided as it favors the reduction of PHA to AN. Considering the biphasic nature of the system, the presence of a surfactant has been found essential to reach high PAP selectivity. Indeed, it could help to stabilize nitrobenzene droplets in solution but it could also act as a phase transfer catalyst to facilitate the migration of PHA to the water phase. Consequently, several commercially available surfactants were tested in the model reaction (Table 5).

Table 5. Screening of surfactants. ${ }^{a}$

Surfactant
Entry



4
S $\oplus_{N}<\mathrm{Cl}^{\ominus}$
$>99$
59
41
5

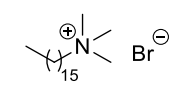
13
46
54
6

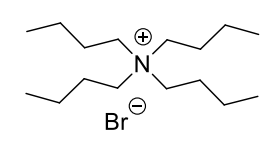
14
43
57
7

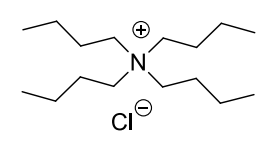
38
45
55
8

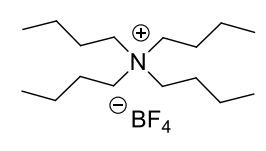
29
54
46
9

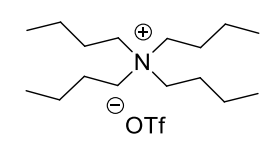
$>99$
76
24
10

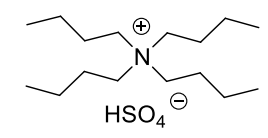
$>99$
84
16

${ }^{a}$ Reaction conditions: Stainless steel reactor, $\mathrm{H}_{2}(10 \mathrm{bar}), \mathrm{NB}(9 \mathrm{~mL}), 1 \mathrm{wt} \%-\mathrm{Pt} / \mathrm{C}(20 \mathrm{mg})$, DMSO (6.5 $\mu \mathrm{L})$, surfactant (2 mol\%), $\mathrm{H}_{2} \mathrm{SO}_{4}(2.5 \mathrm{~mL}), \mathrm{NbO}_{\times} / \mathrm{SiO}_{2}(0.2 \mathrm{~g}), \mathrm{H}_{2} \mathrm{O}(75 \mathrm{~mL}), 80^{\circ} \mathrm{C}$, 14 hours. ${ }^{b}$ Determined by HPLC.

A blank experiment was carried out without any additive in order to establish a benchmark. Under these conditions, the conversion of NB is complete but the selectivity was only $74 \%$ (Table 5, entry 1). Sodium dodecyl sulfate (SDS) was first considered as it is a cheap surfactant that is widely used in many industrial applications. However, this anionic surfactant gave a lower selectivity (Table 5, entry 2). Tributylethylphosphonium ethylsulfate gave a slightly improved 
selectivity but the catalytic activity is very low under these conditions (Table 5, entry 3). Alkyl trimethylammonium salts bearing a benzyl or a hexadecyl chain only gave poor results (Table 5 , entries 4-5). Similarly, tetrabutylammonium bromide $\left(\mathrm{Br}^{-}\right)$, chloride $\left(\mathrm{Cl}^{-}\right)$or tetrafluoroborate $\left(\mathrm{BF}_{4}{ }^{-}\right)$gave poor conversion and selectivity (Table 5, entries 6-8). These poor results could be attributed to the presence of halogen anions that could act as poisons for transition metals. The replacement of halogens by a triflate anion $\left(\mathrm{OTf}^{-}\right)$restored the catalytic activity of the system and the PAP selectivity was slightly improved to $76 \%$ (Table 5, entry 9). Finally, tetrabutylammonium hydrogensulfate (TBAHS) gave full conversion and $84 \%$ selectivity (Table 5, entry 10). The difference observed between OTf and $\mathrm{HSO}_{4}$ anions could be explained by the fact that $\mathrm{HSO}_{4}$ is a protic anion. As a result, it is more likely to act as a phase transfer catalyst rather than a surfactant. The loading of TBAHS was also investigated (Figure 5).

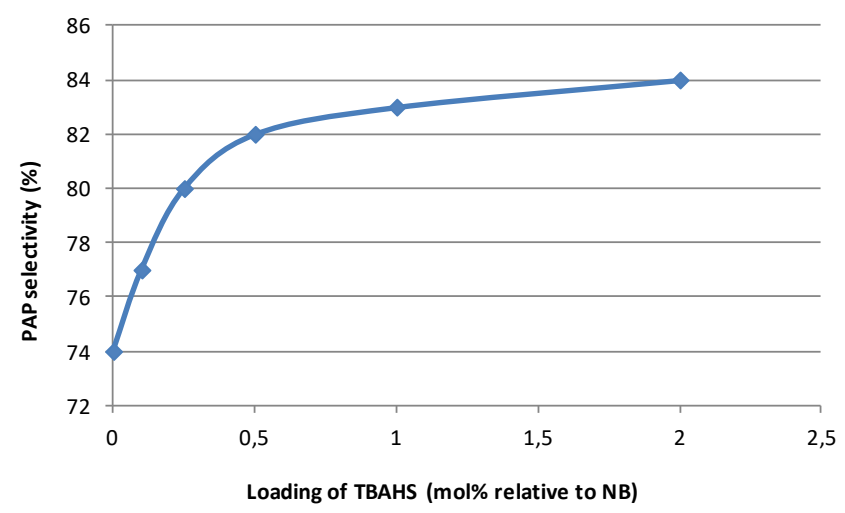

Figure 5. Selectivity of PAP Versus loading of TBAHS. Reaction conditions: Stainless steel reactor, $\mathrm{H}_{2}(10 \mathrm{bar}), \mathrm{NB}(9 \mathrm{~mL}), 1 \mathrm{wt} \%-\mathrm{Pt} / \mathrm{C}(20 \mathrm{mg})$, DMSO $(6.5 \mu \mathrm{L})$, TBAHS $(0-2 \mathrm{~mol} \%)$, $\mathrm{H}_{2} \mathrm{SO}_{4},\left(2.5 \mathrm{~mL}, 0.5\right.$ equiv., $\left.100 \mathrm{~mol} \% \mathrm{H}^{+} / \mathrm{NB}\right), \mathrm{NbO}_{\times} / \mathrm{SiO}_{2}(1 \mathrm{~g}), \mathrm{H}_{2} \mathrm{O}(75 \mathrm{~mL}), 80^{\circ} \mathrm{C}, 14$ hours. The selectivity of PAP was determined determined by HPLC. 
The selectivity progressively increased and reached $84 \%$ when using 2 mol\%. However, further increasing the quantity of TBAHS did not have significant effect on the selectivity. This result is in accordance with typical surfactant concentration found in the literature.

The concentration of NB in the water suspension was next investigated (Table 6). However, considering that nitrobenzene and water are not miscible at room temperature, it is quite inappropriate to refer to a concentration. In that case, we have preferred to use the NB / water $(\mathrm{v} / \mathrm{v})$ ratio.

Table 6. Influence of the nitrobenzene concentration. ${ }^{a}$

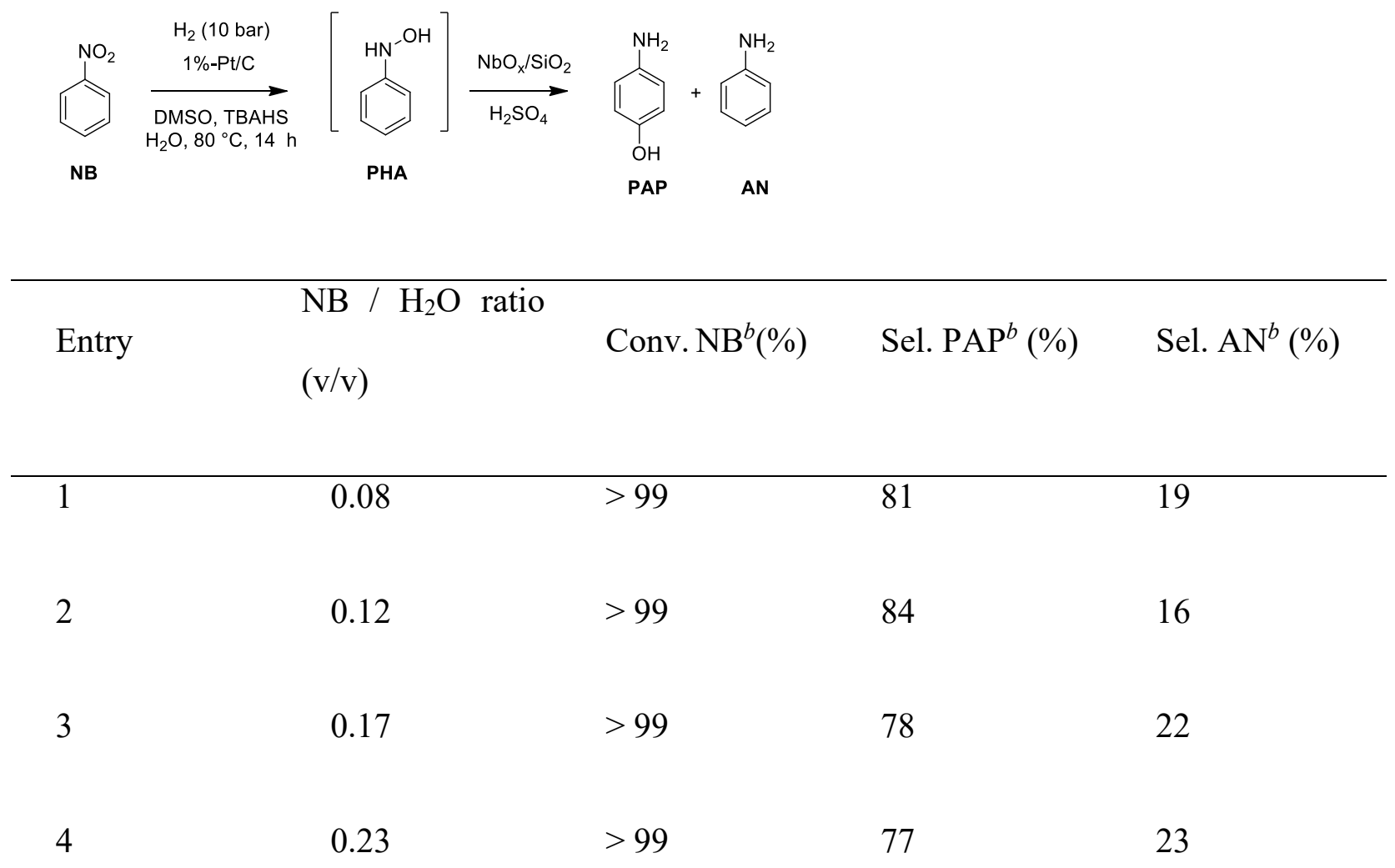

${ }^{a}$ Reaction conditions: Stainless steel reactor, $\mathrm{H}_{2}(10 \mathrm{bar}), \mathrm{NB}(9 \mathrm{~mL}), 1 \mathrm{wt} \%-\mathrm{Pt} / \mathrm{C}(20 \mathrm{mg})$, DMSO (6.5 $\mu \mathrm{L})$, TBAHS (0.6 g), $\mathrm{H}_{2} \mathrm{SO}_{4}(2.5 \mathrm{~mL}), \mathrm{NbO}_{\mathrm{x}} / \mathrm{SiO}_{2}(0.2 \mathrm{~g}), \mathrm{H}_{2} \mathrm{O}(75 \mathrm{~mL}), 80^{\circ} \mathrm{C}, 14$ hours. ${ }^{b}$ Determined by HPLC. 
All experiments led to a complete conversion of NB whatever the ratio used (Table 6, entries 14). However, slight variations of selectivity could be observed depending on the NB quantity. The selectivity was found optimal for a $0.12 \mathrm{NB} /$ water ratio that would correspond, if nitrobenzene were soluble in water, to a $1.05 \mathrm{M}$ concentration (Table 6, entry 2). Under these conditions, the NB droplets should be well dispersed in water.

Considering that the transformation of NB to PAP involves two distinct processes, namely, hydrogenation and Bamberger rearrangement, the optimal temperature is quite difficult to predict. Consequently, this parameter was also studied under the previously optimized conditions (Table 7).

Table 7. Influence of the temperature. ${ }^{a}$

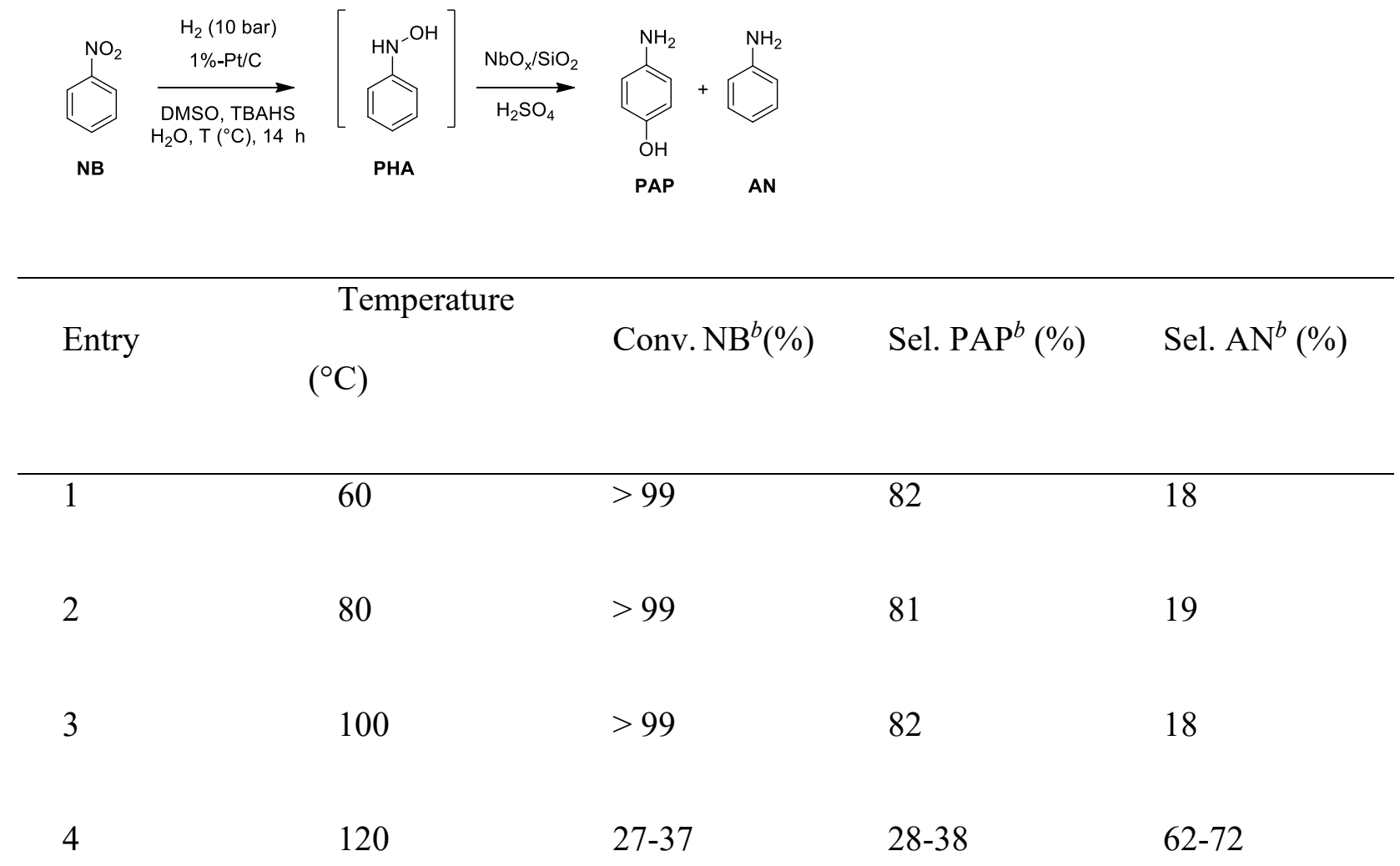


${ }^{a}$ Reaction conditions: Stainless steel reactor, $\mathrm{H}_{2}$ (10 bar), NB (9 mL), 1wt\%-Pt/C (20 mg), DMSO (6.5 $\mu \mathrm{L})$, TBAHS (0.6 g), $\mathrm{H}_{2} \mathrm{SO}_{4}(2.5 \mathrm{~mL}), \mathrm{NbO}_{\mathrm{x}} / \mathrm{SiO}_{2}(0.2 \mathrm{~g}), \mathrm{H}_{2} \mathrm{O}(75 \mathrm{~mL}), 60-120^{\circ} \mathrm{C}$, 14 hours. ${ }^{b}$ Determined by HPLC.

From 60 to $100^{\circ} \mathrm{C}$, the reaction is quite robust as similar conversion and selectivity were obtained (Table 7, entries 1-3). However, at higher temperature, the results were seriously altered and the reaction presents a lack of reproducibility (Table 7, entry 4). This phenomenon has been attributed to the fact that the solubility of NB in water increases with the temperature, ${ }^{35}$ thus increasing the homogeneous character of the system.

All the parameters that could influence the outcome of the reaction have been studied but the PAP selectivity plateaued at about $84 \%$. In order to get further information, the reaction was followed over time. However, given the heterogeneous nature of the mixture, taking samples would necessarily bias the results. Consequently, separate experiments were carried out and stopped at different times (Figure 6).

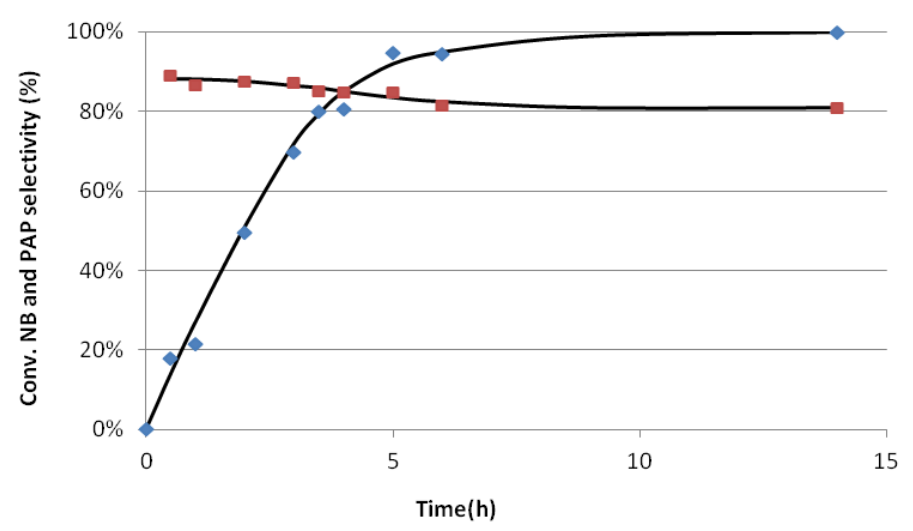

Figure 6. Conversion of NB and PAP selectivity over time. 
After only 30 minutes, the conversion was $20 \%$ and the PAP selectivity almost reached $90 \%$. Then, the selectivity was still $88 \%$ at $50 \%$ conversion. Finally, the PAP selectivity progressively decreased to $81 \%$ after reaching complete conversion.

These results are perfectly consistent with the "droplet" model described by Augustine et al. ${ }^{11 \mathrm{c}}$ and three regimes could be envisioned (Figure 7).

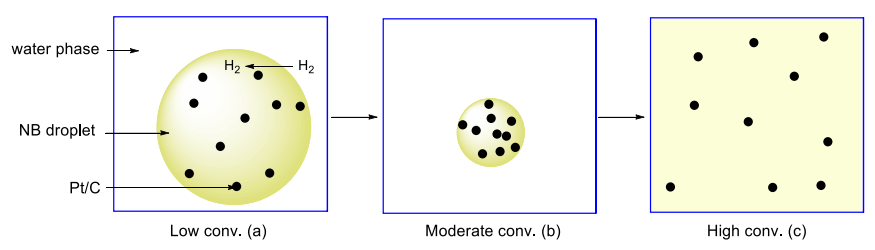

Figure 7. Different regimes of the "droplet" model.

At low conversion, the droplets of NB would be well dispersed in the water phase, thus giving high selectivity (Figure 7, a). At moderate conversion, the size of the droplets would diminish, thus concentrating the catalyst in the droplets but the selectivity should remain quite high (Figure 7, b). However, at high conversion, the solubility limit of NB in water would be reached and the system would become homogeneous. This would lead to over-reduction of PHA in AN, thus reducing the selectivity (Figure 7, c).

From this mechanistic rationale, it can be concluded that it is important to carry out the reaction at incomplete conversion in order to preserve the droplets and to maintain high PAP selectivity. Actually, this is the strategy that is currently employed at the industrial scale. For comparison purposes, a scale-up reaction was carried out under our optimized conditions using $174 \mathrm{mmol}$ of nitrobenzene (Scheme 2). 


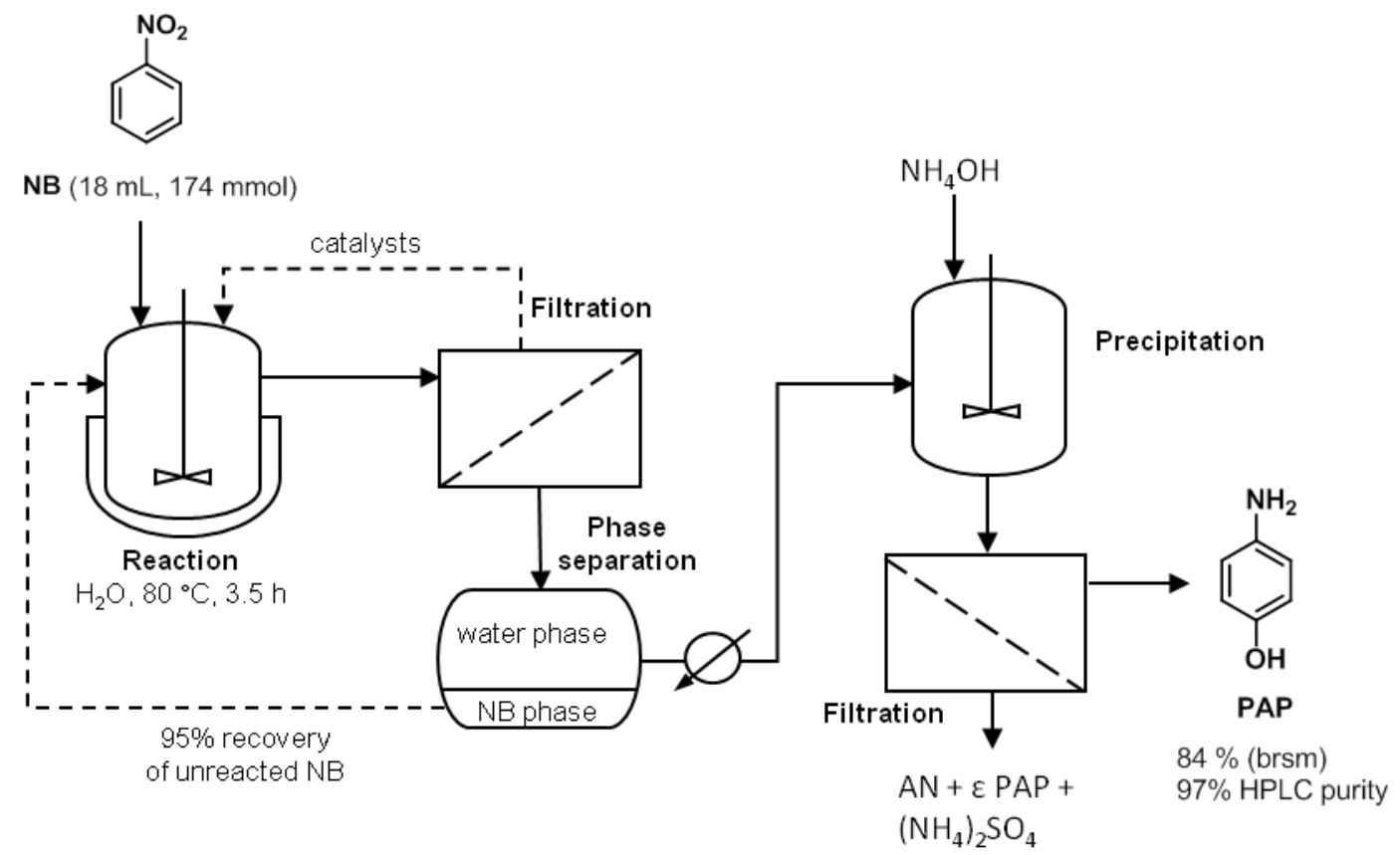

Scheme 2. Scale-up reaction on the laboratory scale.

The reaction was stopped after $3.5 \mathrm{~h}$ to give a $50 \%$ conversion. The catalysts were filtered and $95 \%$ of unreacted NB was recovered from the filtrate by decantation. The remaining water phase was basified using aqueous ammonia until $\mathrm{pH} 8$ in order to precipitate PAP that was filtered and washed with water. Following this procedure, PAP was obtained with $84 \%$ isolated yield (based on the remaining starting material). HPLC of the crude product revealed that the purity was about 97\%, the main byproduct being ortho-aminophenol (OAP) (about 3\%) (Figure 8).

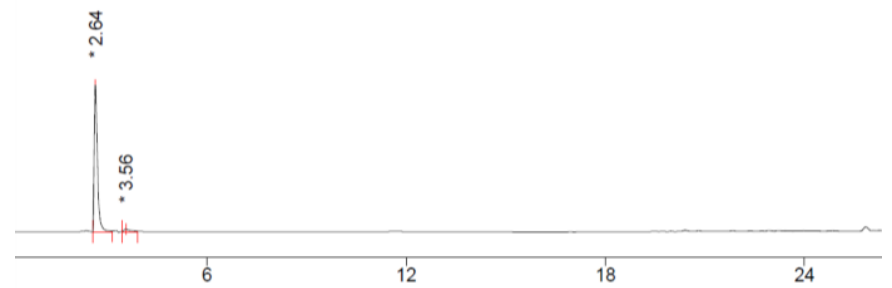


Figure 8. HPLC chromatogram of crude PAP. Retention times: $2.64 \mathrm{~min}$ (PAP, 97\%), $3.56 \mathrm{~min}$ (OAP, 3\%). See Supporting Information for full details.

If necessary, the purity of PAP could be further improved to $>99 \%$ by recrystallisation. The filtrate was also analyzed and mainly contains $\left(\mathrm{NH}_{4}\right)_{2} \mathrm{SO}_{4}, \mathrm{AN}$ and some traces of PAP.

In order to fully evaluate the potential of this method, the recovery and recycling of catalysts was also studied over 5 runs (Figure 9).
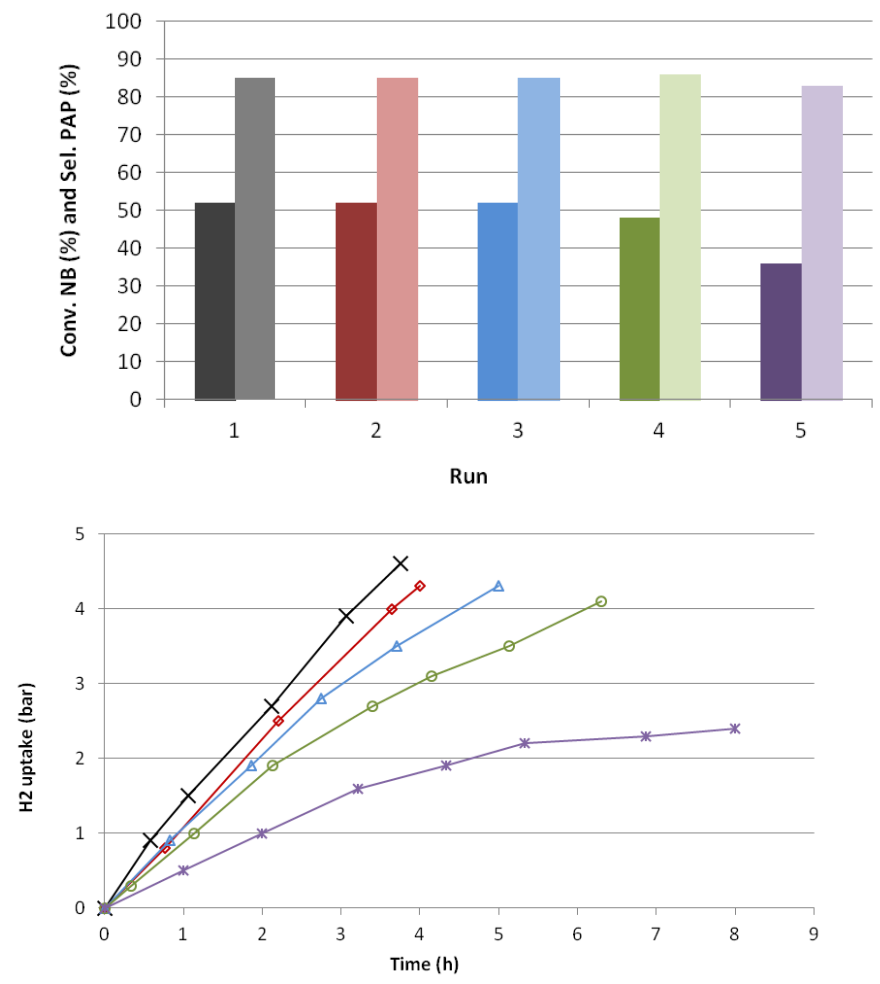

Figure 9. Recycling of the catalysts. Top: - Conversion of NB (\%); - Selectivity of PAP (\%). Bottom: Uptake of hydrogen over time.

For each reaction, the conversion was stopped around 50\% conversion (the hydrogen uptake was monitored). Then, the mixture of $1 \%-\mathrm{Pt} / \mathrm{C}$ and $\mathrm{NbO}_{\mathrm{x}} / \mathrm{SiO}_{2}$ was filtered, washed with toluene and $\mathrm{MeOH}$ and dried under vacuum. The resulting mixture was directly re-used for the next batch. 
From these experiments, the catalytic system proved to be efficient over the first 4 runs with about $48-52 \%$ conversion of NB and $85-86 \%$ PAP selectivity (Figure 9, top). However, the reaction time should be progressively increased to reach about 50\% conversion (Figure 9, bottom). This could be explained by partial deactivation of the catalytic system but also by the mass loss of catalysts during each filtration, representing about $15 \%$ between run 1 and run 5 . Indeed, the adjustment of the quantity of both $\mathrm{Pt} / \mathrm{C}$ and $\mathrm{NbO}_{\mathrm{x}} / \mathrm{SiO}_{2}$ to the original amount restored the catalytic properties of the mixture.

Finally, the results obtained were compared with those of the Mallinckrodt process employing excess sulfuric acid for the Bamberger rearrangement and giving the best selectivity (Table 8).

Table 8. Comparison with the Mallinckrodt process.
Entry
Parameter
Mallinckrodt process $8^{\mathrm{e}}$
This work

\begin{tabular}{llll}
\hline 1 & $\mathrm{H}^{+} / \mathrm{NB}$ ratio & 1.8 & 0.5 \\
2 & Conv. $\mathrm{NB}^{b}(\%)$ & 59 & 50 \\
3 & & 85 & $85-88$ \\
4 & $\mathrm{Sel.} \mathrm{PAP}^{b}(\%)$ & & 0.76
\end{tabular}

The conditions employing $\mathrm{NbO}_{x} / \mathrm{SiO}_{2}$ as an acid co-catalyst allow the reduction of the quantity of $\mathrm{H}_{2} \mathrm{SO}_{4}$ by more than 3-fold while keeping similar performances (Table 8, entries 1-3). Consequently, the quantity of $\left(\mathrm{NH}_{4}\right)_{2} \mathrm{SO}_{4}$, produced by neutralization, was drastically reduced from 2.2 to $0.76 \mathrm{Kg}$ per $\mathrm{Kg}$ of PAP (Table 8, entry 4). This highlights the potential of using a mixture of heterogeneous and homogeneous acid catalysts. 


\section{CONCLUSION}

In conclusion, we have demonstrated that the association of a heterogeneous niobium-based catalyst with a mineral acid could be beneficial for the preparation of para-aminophenol (PAP) from nitrobenzene through Bamberger rearrangement. Under these conditions, PAP was obtained with $85-88 \%$ selectivity that is representing a $10 \%$ selectivity improvement by comparison with sulphuric acid alone. Moreover, this system allowed the reduction of the quantity of sulphuric acid by 3. As a consequence, less ammonia was required for neutralization, thus reducing the generation of saline waste of the traditional process. Further studies will focus upon applying this strategy to other acid catalyzed transformations.

\section{ASSOCIATED CONTENT}

Supporting Information. HPLC method, general procedures, ${ }^{1} \mathrm{H}$ and ${ }^{13} \mathrm{C}$ NMR spectra of paraaminophenol. This material is available free of charge via the internet at http://pubs.acs.org.

\section{AUTHOR INFORMATION}

\section{Corresponding Author}

* E-mail: nicolas.duguet@univ-lyon1.fr

ORCID

Nicolas Duguet: 0000-0002-9425-7450

* E-mail: marc.lemaire.chimie@univ-lyon1.fr

ORCID

Marc Lemaire: 0000-0003-2800-0590

\section{Notes}


The authors declare no competing financial interest.

\section{ACKNOWLEDGMENT}

The authors would like to thank Minakem and the Association Nationale de la Recherche et de la Technologie (ANRT) for financial support through a CIFRE grant (2011/1190) for Roxan Joncour. Léa Vilcocq from "Laboratoire de Génie des Procédés Catalytiques" (LGPC) is also warmly thanked for her help with the $\mathrm{NH}_{3}$-TPD measurements.

\section{ABBREVIATIONS \\ NB, nitrobenzene; PAP, para-aminophenol, PHA, phenyl hydroxylamine; AN, aniline; OAP, ortho-aminophenol; AOB, azoxybenzene; DMSO, dimethyl sulfoxide; TBAHS, tetrabutylammonium hydrogensulfate.}

\section{REFERENCES}

1 Mitchell, S. C.; Waring, R. H. Aminophenols in Ullmann's Encyclopedia of Industrial Chemistry, John Wiley \& Sons, 2000.

2 Acetaminophen (Paracetamol) Market for Pharmaceuticals, Dye Industry and Chemical Industry - Global Industry Perspective, Comprehensive Analysis, Size, Share, Growth, Segment, Trends and Forecast, 2014 - 2020, Zion Research, 2015.

${ }^{3}$ a) Joncour, R.; Duguet, N.; Metay, E.; Ferreira, A.; Lemaire, M. Green Chem. 2014, 16, 29973002; b) Lemaire, M.; Joncour, R.; Duguet, N.; Metay, E.; Ferreira, A. Eur. Patent 2860172, 2015.

4 a) Béchamp, M. A. Ann. Chim. Phys. 1854, 3, 186-196; b) Lyons, R E; Smith, L. T. Chem. Ber. 1927, 60, 173-182. 
5 a) Xie, M.; Zhang, F.; Long, Y.; Ma, J. RSC Adv. 2013, 3, 10329-10334; b) Czaplik, W. M.; Neudörfl, J.-M.; Jacobi von Wangelin, A. Green Chem. 2007, 9, 1163-1165; c) Vaidya, M. J.; Kulkarni, S. M.; Chaudhari, R. V. Org. Process Res. Dev. 2003, 7, 202-208.

${ }^{6}$ a) Bamberger, E. Ber. Dtsch. Chem. Ges. 1894, 27, 1347-1350; b) Bamberger, E. Ber. Dtsch. Chem. Ges. 1900, 33, 3600-3622.

${ }^{7}$ a) Henke, C. O.; Vaughen, J. V. US Patent 2,198,249, 1940; b) Rylander, P. N.; Karpenko, I. M.; Pond, G. R. U.S. Patent 3,715,397, 1970; c) Greco, N. P. U.S. Patent 3,953,509, 1976.

8 a) Sathe, S. S. US Patent 4,176,138, 1978; b) Dunn, T. US Patent 4,264,529, 1981; c) Derrenbacker, E. L. US Patent 4,307,249, 1981; d) Caskey, D. C.; Chapman, D. W. US Patent 4,415,753, 1983; e) Caskey, D. C.; Chapman D. W. US Patent 4,571,437, 1986; f) Miller, D. C. US Patent 5,312,991, 1994.

${ }^{9}$ Zou, L.; Cui, Y.; Dai, W. Chin. J. Chem. 2014, 32, 257-262.

${ }^{10}$ Gao, Y.; Wang, F.; Lia, S.; Yu, D. React. Kinet. Catal. Lett. 1998, 64, 351-357.

11 a) Nadgeri; J. M.; Biradar, N. S.; Patil, P. B.; Jadkar, S. T.; Garade, A. C.; Rode, C. V. Ind. Eng. Chem. Res. 2011, 50, 5478-5484; b) Min, K.-I.; Choi, J.-S.; Chung, Y.-M.; Ahn, W.-S.; Ryoo, R.; Lim, P. K. Appl. Catal., A 2008, 337, 97-104; c) Tanielyan, S. K.; Nair, J. J.; Marin, N.; Alvez, G.; McNair, R. J.; Wang, D.; Augustine R. L. Org. Process Res. Dev. 2007, 11, 681688; d) Rode, C. V.; Vaidya, M. J.; Jaganathan, R.; Chaudhari, R. V. Chem. Eng. Sci. 2001, 56, 1299-1304; e) Rode, C. V.; Vaidya, M. J.; Chaudhari, R. V. Org. Process Res. Dev. 1999, 3, 465-470; f) Juang, T.-M.; Hwang, H.-C.; Ho, H.-O.; Chen, C.-Y. J. Chin. Chem. Soc. 1988, 35, $135-140$. 
12 a) Dong, Z.; Wang, T.; Zhao, J.; Fu, T.; Guo, X.; Peng, L.; Zhao, B.; Xue, N.; Ding, W.; Xie, Z. Applied Catal., A 2016, 520, 151-156; b) Rode, C. V.; Vaidya, M. J.; Chaudhari, R. V. US Patent 6,403,833, 2002.

${ }^{13}$ Chaudhari, R. V.; Divekar, S. S.; Vaidya, M. J.; Rode, C. V. US Patent 6,028,227, 2000.

${ }^{14}$ Liu, P.; Hu, Y.; Ni, M.; You, K.; Luo, H. Catal. Lett. 2010, 140, 65-68.

${ }^{15}$ Wang, S.; Wang, Y.; Gao, Y.; Zhao, X. Chin. J. Catal. 2010, 31, 637-644.

${ }^{16}$ Liu, X.; Fang, Y.; Lu, X.; Wei, Z.; Li, X. Chem. Eng. J. 2013, 229, 105-110.

17 a) Jeeva Ratnam, K.; Sudarshan Reddy, R.; Sekhar, N. S.; Lakshmi Kantam, M.; Deshpande, A.; Figueras F. Appl. Catal., A 2008, 348, 26-29; b) Deshpande, A.; Figueras, F.; Lakshmi Kantam, M.; Jeeva Ratnam, K.; Sudarshan Reddy, R.; Sekhar, N. S. J. Catal. 2010, 275, 250256.

${ }^{18}$ Haynes, W.M. (ed.). CRC Handbook of Chemistry and Physics. 95th Edition. CRC Press LLC, Boca Raton: FL 2014-2015, p. 4-101.

${ }^{19}$ Komatsu, T.; Hirose, T. Appl. Catal., A. 2004, 276, 95-102.

${ }^{20}$ Wang, S.; Ma, Y.; Wang, Y.; Xue, W.; Zhao, X. J. Chem. Technol. Biotechnol. 2008, 83, $1466-1471$.

${ }^{21}$ a) Wang, S; Jin, Y.; He, B.; Wang, Y.; Zhao, X. Sci. China: Chem. 2010, 53, 1514-1519; b) Wang, S.; He, B.; Wang, Y.; Zhao, X. Catal. Commun. 2012, 24, 109-113.

22 a) Zhang, T.-T.; Jiang, J.-Y.; Wang, Y.-H. Org. Process Res. Dev. 2015, 19, 2050-2054; b) Zhang, T.-T.; Jiang, J.-Y.; Wang, Y.-H. Chin. Chem. Lett. 2017, 28, 307-311.

23 a) Tanabe, K. Catal. Today 2003, 78, 65-77; b) Ziolek, M. Catal. Today 2003, 78, 47-64; c) Nowak, I.; Ziolek, M. Chem. Rev. 1999, 99, 3603-3624.

24 Tanabe, K. Mater. Chem. Phys. 1987, 17, 217-225. 
25 a) Lebarbier, V.; Houalla, M., Onfroy, T. Catal. Today 2012, 192, 123-129; b) Carniti, P.; Gervasini, A.; Biella, S.; Auroux, A. Catal. Today 2006, 118, 373-378; c) Armaroli, T.; Busca, G.; Carlini, C.; Giuttari, M.; Raspolli Galleti, A. M.; Sbrana, G. J. Mol. Catal. A: Chem. 2000, $151,233-243$.

${ }^{26}$ Paulis, M.; Martín, M.; Soria, D. B.; Díaz, A.; Odriolzola, J. A.; Montes, M. Appl. Catal., A. 1999, $180,411-420$.

${ }^{27}$ Morais, M.; Torres, E. F.; Carmo, L. M. P. M.; Pastura, N. M. R.; Gonzalez, W. A.; dos Santos, A. C. B.; Lachter, E. R. Catal. Today 1996, 28, 17-21

${ }^{28}$ Bassan, I. A. L.; Nascimento, D. R.; San Gil, R. A. S.; Pais da Silva, M. I.; Moreira, C. R.; Gonzalez, W. A.; Faro Jr., A. C.; Onfroy, T.; Lachter, E. R. Fuel Process. Technol. 2013, 106, 619-624.

${ }^{29}$ a) Kitano, T.; Shishido, T.; Teramura, K.; Tanaka, T. J. Phys. Chem. C 2012, 116, 1161511625; b) Abdel-Rehim, M. A.; dos Santos, A. C. B.; Camorim, V. L. L.; da Costa Faro Jr., A. Appl. Catal., A. 2006, 305, 211-218; c) Tanabe, K. Catal. 2003, 78, 65-77.

${ }^{30}$ Sumiya, S.; Oumi, Y.; Sadakane, M.; Sano, T. Appl. Catal., A. 2009, 365, 261-267.

${ }^{31}$ Ye, F.; Zhang, D.; Xue, T.; Wang, Y.; Guan, Y. Green Chem. 2014, 16, 3951-3957.

${ }^{32}$ Anilkumar, M.; Hoelderich, W. F. J. Catal. 2012, 293, 76-84; b) Anilkumar, M.; Hoelderich, W. F. Catal. Today 2012, 198, 289-299; c) Anilkumar, M.; Hoelderich, W. F. Appl. Catal., B 2015, 165, 87-93; d) Maronna, M. M.; Kruissink, E. C.; Parton, R. F.; Tinge, J. T.; Soulimani, F.; Weckhuysen, B. M.; Hoelderich, W. F. Appl. Catal., B 2016, 185, 272-280; Maronna, M. M.; Kruissink, E. C.; Parton, R. F.; Tinge, J. T.; Hoelderich, W. F. Catal. Commun. 2017, 90, $23-26$. 33 The solubility of hydrogen in nitrobenzene is $2.1 \mathrm{mmol} / \mathrm{L} / \mathrm{bar}$ at $80^{\circ} \mathrm{C}$ (Rhadhakrishnan, $\mathrm{K}$.; Ramachandran, P. A.; Brahme, P. H.; Chaudhari, R. V. J. Chem. Eng. Data 1983, 28, 1-4) 
whereas it is only $0.71 \mathrm{mmol} / \mathrm{L} / \mathrm{bar}$ in water at the same temperature (Jáuregui-Haza, U. J.;

Pardillon-Fontdevilla, E. J.; Wilhelm, A. M.; Delmas, H. Lat. Am. Appl. Res. 2004, 34, 71-74).

${ }^{34}$ See Supporting Information for full details

${ }^{35}$ Vermillon, H. E.; Werbel, B.; Saylor, J. H.; Gross, P. M. J. Am. Chem. Soc. 1941, 63, 13461347. 